\title{
LETTER
}

\section{Is routine autopsy in the intensive care unit viable?}

\author{
Armand RJ Girbes' and Jan G Zijlstra*2 \\ See related review by De Vlieger et al., http://ccforum.com/content/14/2/221
}

In the previous issue of Critical Care, De Vlieger and colleagues [1] share their view on the value of autopsy in the intensive care unit (ICU). They are disappointed by the declining frequency of routine autopsy in the ICU. The arguments in favor are repeated and the arguments against are refuted as before. We will not do that again. Despite this understandable reasoning, it is a fact of life that the autopsy rate is declining. Are we missing the real point? We have some additional arguments that the authors failed to mention. Nowadays doctors are taught that diagnostic tools are to be used only when indicated and when there is a clear diagnostic purpose. We do not, for example, perform a computed tomography scan after every physical exam. Asking for an autopsy, more or less for the purpose of 'seeing what one can find', is counterintuitive. Autopsy is then used as a diagnostic screening test although it lacks most of the essentials - in terms of sensitivity and specificity - that are required for that use.

Many of the discussions between clinician and pathologist deal with the question 'with' or 'because of' and 'post aut propter'. Is the pulmonary embolism or the pneumonia a perimortal phenomenon not searched for in the setting aiming for comfort, or is one or the other really the missed cause of death? Clinicians, correctly, do not always consider the pathologist to be the gold standard.
In the era of evidence-based medicine, we diagnose and treat patients according to guidelines. These are based on extensive literature searches and consensus. How do we fit in the results of one autopsy? Autopsy will always be a nonrandom sample from a small selected population. It seems to have the evidence-based medicine grading of case reports. Undoubtedly, autopsy can be an important tool in research and it can be offered to families that have serious remaining questions. But routine autopsy is a 'dead man walking'.

Abbreviation

$\mathrm{ICU}$, intensive care unit.

Competing interests

The authors declare that they have no competing interests.

\section{Author details}

'Free University Medical Center, Boelelaan 1117, 1081 HV Amsterdam, The Netherlands. ${ }^{2}$ University Medical Center Groningen, University of Groningen, Hanzeplein 1, 9730 EZ RB Groningen, The Netherlands.

Published: 30 June 2010

\section{Reference}

1. De Vlieger GYA, Mahieu EMJL, Meersseman W: Clinical review: What is the role for autopsy in the ICU? Crit Care 2010, 14:221.

\section{doi:10.1186/cc9069}

Cite this article as: Girbes ARJ, Zijlstra JG: Is routine autopsy in the intensive care unit viable? Critical Care 2010, 14:425. 